\title{
Atlanto-axial rotary instability (Fielding type 1): characteristic clinical and radiological findings, and treatment outcomes following alignment, fusion, and stabilization
}

\author{
Fraser C. Henderson $\mathrm{Sr}^{1,2,3}$ (D) Robert Rosenbaum ${ }^{1,2,3,4} \cdot$ Malini Narayanan $^{1,2,3} \cdot$ Myles Koby $^{2} \cdot$ Kelly Tuchman $^{3} \cdot$ \\ Peter C. Rowe ${ }^{5}$. Clair Francomano ${ }^{6}$
}

Received: 18 March 2020 / Revised: 22 June 2020 / Accepted: 26 June 2020 / Published online: 4 July 2020

(C) The Author(s) 2020

\begin{abstract}
Atlanto-axial instability (AAI) is common in the connective tissue disorders, such as rheumatoid arthritis, and increasingly recognized in the heritable disorders of Stickler, Loeys-Dietz, Marfan, Morquio, and Ehlers-Danlos (EDS) syndromes, where it typically presents as a rotary subluxation due to incompetence of the alar ligament. This retrospective, IRB-approved study examines 20 subjects with Fielding type 1 rotary subluxation, characterized by anterior subluxation of the facet on one side, with a normal atlanto-dental interval. Subjects diagnosed with a heritable connective tissue disorder, and AAI had failed nonoperative treatment and presented with severe headache, neck pain, and characteristic neurological findings. Subjects underwent a modified Goel-Harms posterior C1-C2 screw fixation and fusion without complication. At 15 months, two subjects underwent reoperation following a fall (one) and occipito-atlantal instability (one). Patients reported improvement in the frequency or severity of neck pain $(P<0.001)$, numbness in the hands and lower extremities $(P=0.001)$, headaches, pre-syncope, and lightheadedness (all $P<0.01$ ), vertigo and arm weakness (both $P=0.01$ ), and syncope, nausea, joint pain, and exercise tolerance (all $P<0.05$ ). The diagnosis of Fielding type $1 \mathrm{AAI}$ requires directed investigation with dynamic imaging. Alignment and stabilization is associated with improvement of pain, syncopal and near-syncopal episodes, sensorimotor function, and exercise tolerance.
\end{abstract}

Keywords Atlanto-axial $\cdot$ Rotary subluxation $\cdot$ Dynamic imaging $\cdot$ Alar ligament $\cdot$ Syncope $\cdot \mathrm{C} 1-\mathrm{C} 2$ fusion

\section{Introduction}

Atlanto-axial instability (AAI) results most commonly from trauma, due to injury of the transverse odontoid ligament,

Fraser C. Henderson, Sr

henderson@fraserhendersonmd.com

1 Department of Neurosurgery, University of Maryland Capital Region Health Prince George's Hospital Center, Cheverly, MD, USA

2 Doctors Community Hospital, Lanham, MD, USA

3 Metropolitan Neurosurgery Group LLC, Silver Spring, MD, USA

4 Department of Neurosurgery, Walter Reed-Bethesda National Military Medical Center, Bethesda, MD, USA

5 Department of Pediatrics, Johns Hopkins University, Baltimore, MD, USA

6 Medical and Molecular Genetics, Indiana University Health Physicians, Indianapolis, IN, USA less commonly from congenital conditions such as os odontoideum or Klippel-Feil syndrome, and least commonly neoplasm or infection. The last few decades have witnessed increased recognition of AAI in the connective tissue disorders, including inflammatory disorders (such as rheumatoid arthritis, systemic lupus erythematosus, Stihl disease, ankylosing spondylitis) and heritable disorders, such as Ehlers-Danlos (EDS), Stickler, Loeys-Dietz, Marfan, and Morquio syndromes (Mucopolysacharridosis IV) [7]; spondyloepiphyseal dysplasia; and congenital hemifacial microsomia conditions, such as Goldenhar syndrome. AAI can also occur with minimal or no trauma in children as a result of ligament laxity [82]. And developmental conditions, such as atlanto-occipital segmentation failure - the HOX-D3 homeotic transformation - are also recognized as predisposing to AAI.

The atlanto-axial joint, the most mobile in the body, is stabilized primarily by ligaments [10]. Therefore, AAI is not uncommon in conditions of lax ligaments. Down syndrome 
has an 11 to $17 \%$ incidence of AAI [21, 29, 34, 66, 77]. Of Halko's 4 subjects with vascular EDS, three had AAI [38]. One-third of children with ligamentous laxity due to congenital spondyloepiphyseal dysplasia suffered from AAI with cervical myelopathy [70]. Healey reported on eight subjects with Goldenhar syndrome, of which three had AAI [40]. The inflammatory connective tissue disorders are no exception: prior to the development of effective disease-modifying pharmacotherapies, $88 \%$ of rheumatoid arthritis patients exhibited radiographic evidence of C1-C2 involvement, $49 \%$ were symptomatic, $20 \%$ were myelopathic, and $10 \%$ succumbed to death $[23,68]$.

While others have reported open reduction of fixed subluxation in children with neck deformity but no significant functional or neurological symptoms [33], this study addresses Fielding type 1 rotary subluxations (AAI) in patients with substantial functional and neurological symptoms, in the context of hereditable connective tissue disorders. This cohort is comprised primarily of EhlersDanlos syndrome, hypermobility type (designated as hEDS), in whom the diagnosis of AAI requires dynamic imaging, such as rotational $\mathrm{CT}$ of $\mathrm{C} 1-2$ to show pathological angular displacement, or lateral neck tilting to demonstrate lateral displacement [63].

AAI Fielding type 1 subluxations are characterized by anterior displacement of the facet primarily on one side, with a normal atlanto-dental interval. This form of AAI, found predominantly in the hereditary connective tissue disorder populations, is due to alar ligament incompetence, as opposed to the transverse ligament failure in rheumatoid arthritis and Down syndrome.

Lightheadedness was present in every patient, with syncope or pre-syncope reported by $75 \%$. Measurement of preoperative symptoms before and after stabilization of the C1$\mathrm{C} 2$ motion segment supports the observation that the somatic and autonomic nervous system is materially and adversely effected by mechanical deformation of the neuraxis and instability at the $\mathrm{C} 1-\mathrm{C} 2$ level, and that there are substantial and salutary benefits to neurological function with the elimination of this deformity and instability.

\section{Materials and methods}

\section{Subject enrollment}

A cohort of 20 subjects diagnosed with EDS, or in one case, unspecified hereditary connective tissue disorders (HCTD), was enrolled retrospectively in an IRB approved study (Greater Baltimore Medical Center). All subjects had undergone $\mathrm{C} 1-\mathrm{C} 2$ reduction, fusion, and stabilization for atlanto-axial instability between 2017 and 2018 at a single institution by the authors (FCH, RR). The subjects were taken consecutively, with the exception that three patients (who did not respond to the lengthy questionnaires) were replaced with three subjects next on the list. The subjects were composed of 16 females and 4 males from 11 different states, age 18-54 years, average age 34 years at time of surgery.

\section{Evaluation}

Most of the patients had been evaluated by the geneticist (CF). Pain was assessed by the visual analog scale for pain $(0-10$ / 10 ) before and after surgery (range 12-24 months). Neurological symptoms were assessed by a comprehensive standardized questionnaire. The neurologic exams were performed by the neurosurgeons (FCH, RR, MN).

Participants were contacted by a third party 12-24 months following surgery, and asked to recall the frequency of symptoms in the month before surgery and in the month before post-operative questionnaire completion, and these were cross-checked with the symptom pre-operative questionnaire for accuracy. The frequency of symptoms was reported using a 5-point scale (never, 1-3 times/month, once weekly, multiple times weekly, and daily). The severity of symptoms was ranked on a 4-point scale (no symptoms, mild, moderate, severe).

Respondents also completed a Karnofsky Performance score and the Short Form Health Survey (SF-36) physical functioning subscale (which assess difficulty with activities such as running, lifting, bending, stooping, walking several hundred yards to a mile and climbing several flights of stairs). Subjects recorded their ability to return to work. At follow-up, participants also completed a Global Clinical Impression of Change score, which asked them to grade the changes in activity, symptoms, and quality of life since the $\mathrm{C} 1-\mathrm{C} 2$ surgery using a 7-point scale (no change or condition has gotten worse, almost the same, hardly any change at all, a little better but no noticeable change, somewhat better but the change has not made any real difference, moderately better and a slight but noticeable change, better, and a definite improvement that has made a real and worthwhile difference, or a great deal better and a considerable difference that has made all the difference).

Pre- and post-operative radiological measurements were made by the neuroradiologist (MK). Subjects underwent pre-operative computerized tomography (CT) of the cervical spine, with the neck maximally rotated (usually 75 to $90^{\circ}$ ) to the left and to the right (Fig. 1). The axial views of $\mathrm{C} 1$ and $\mathrm{C} 2$ upon full-neck rotation were measured from the 12 o'clock position; the angle of rotation of $\mathrm{C} 2$ is subtracted from the angle of rotation of $\mathrm{C} 1$. Angular displacement between $\mathrm{C} 1$ and $\mathrm{C} 2$ of $>41^{\circ}$ was considered pathological. When 3D CT reconstruction was available, the percentage $\mathrm{C} 1-\mathrm{C} 2$ facet 
subluxation was assessed (Fig. 2). Post-operative CT was performed at 3-16 months to assess fusion and alignment.

\section{Statistical analysis}

For comparisons of pre- and post-operative data for each participant, we used paired $t$ tests for normally distributed data, and the Wilcoxon paired ranks test for paired ordinal data or for continuous variables that were not normally distributed. Statistical analyses were conducted using IBM Statistics SPSS version 25 (IBM Statistics, New York), and illustrations were prepared using GraphPad Prism version 8.3.0 for Windows (GraphPad Software, La Jolla, CA, USA, www.graphpad. com). $P$ values reported as $<0.05$ were in the $0.01<P<0$. 05 range, and $P$ values reported as $<0.01$ were in the 0.001 $<P<0.01$ range.

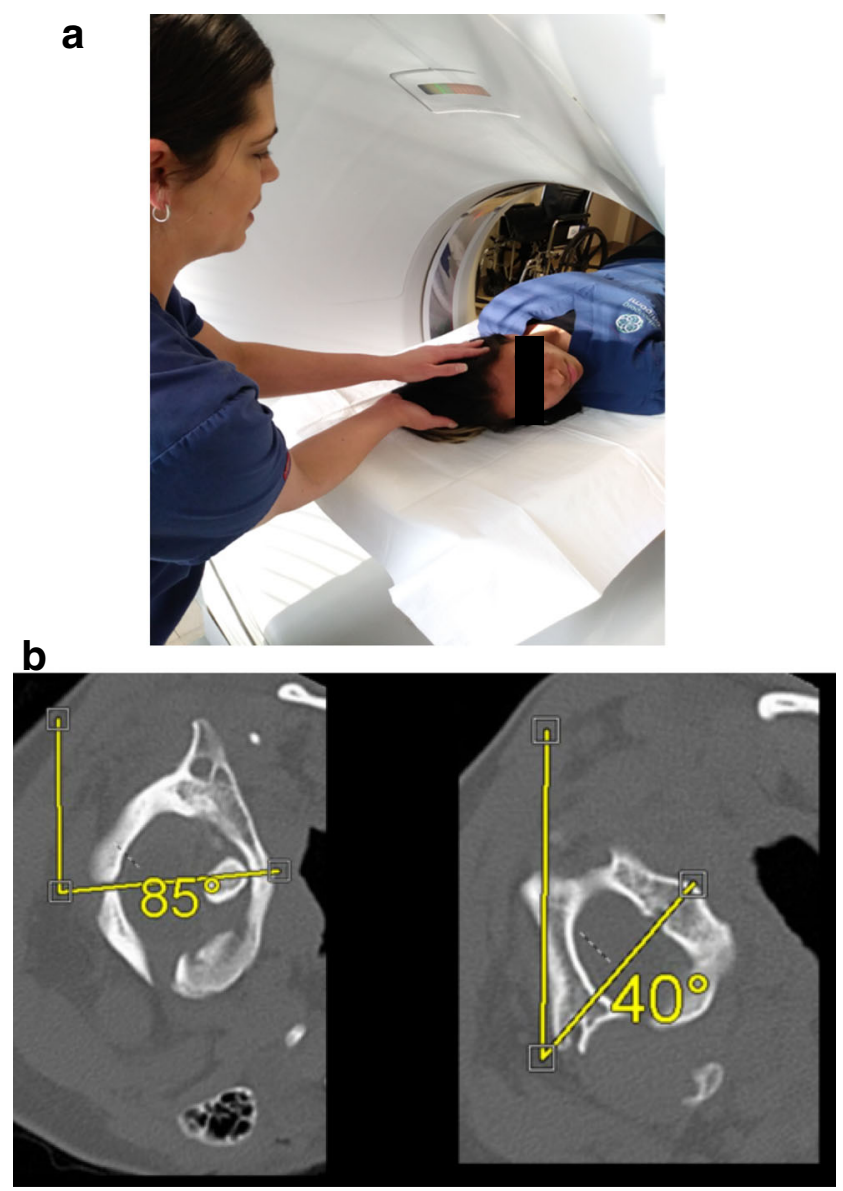

Fig. 1 a To assess for alar ligament incompetence and possible subluxation between $\mathrm{C} 1$ and $\mathrm{C} 2$, a dynamic $\mathrm{CT}$ of the upper cervical spine is performed. A CT scan is performed with the patient lying supine, with the head rotated fully to the left, then rescanned with the head rotated fully to the right, as shown in b. b Axial CT view through C1 and $\mathrm{C} 2$, showing the angle deviation from the neutral position (12 o'clock position). The angle subtended by $\mathrm{C} 1$ minus the angle subtended by $\mathrm{C} 2$ is the angle between $\mathrm{C} 1$ and $\mathrm{C} 2$. In this case, the angle subtended between $\mathrm{C} 1$ and $\mathrm{C} 2$ is $85^{\circ}$ minus $40^{\circ}$ equals $45^{\circ}$, which exceeds the pathological threshold of $42^{\circ}$

\section{Inclusion criteria for C1-C2 fusion surgery}

All subjects met the following criteria:

i. Formal genetics evaluation and diagnosis with a hereditary connective tissue disorder.

ii. Severe headache and/or neck pain for greater than 6 months.

iii. Symptoms compatible with atlanto-axial instability [5, 69].

iv. Congruent neurological deficits.

v. Radiological findings - an angle subtended by $\mathrm{C} 1-\mathrm{C} 2$ greater than $41^{\circ}$ (Fig. 1b), and/or C1-C2 facet overlap of less than $10 \%$ (Fig. 2a and b). In some cases, radiological findings were augmented by fluoroscopic demonstration of pathological translation on lateral tilt $>3.5 \mathrm{~mm}$ on open mouth views $[18,26]$. (Fig. 3)
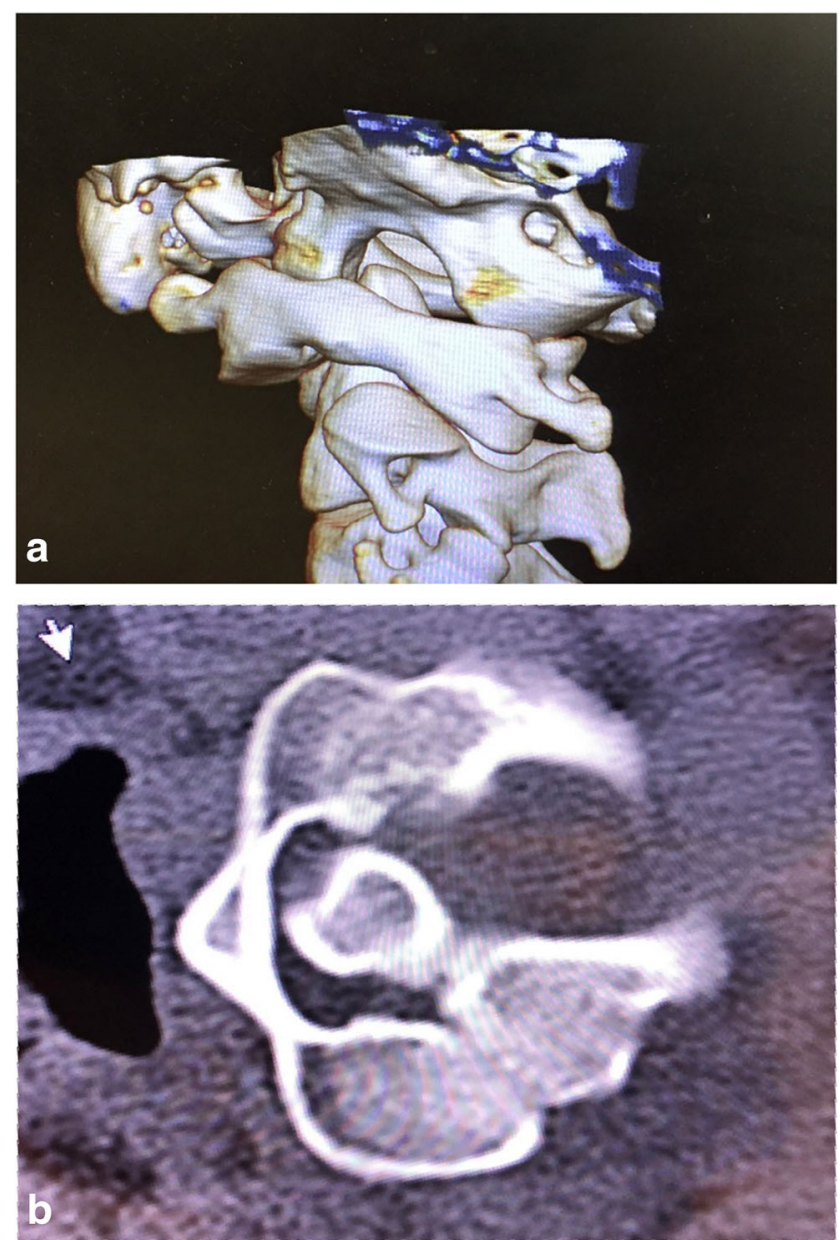

Fig. 2 a A 3D CT reconstruction of the cervical spine rotated to the left shows that the left superior facet of $\mathrm{C} 2$ is more than $90 \%$ exposed, and, therefore, defined as subluxed. b Axial CT of $\mathrm{C} 1$ and $\mathrm{C} 2$ showing neck rotation to the right. Note the Fielding type 1 subluxation, with anterior subluxation of the left $\mathrm{C} 1$ facet (anterior to the left $\mathrm{C} 2$ facet), while the atlanto-dental interval - between the anterior tubercle and the odontoidremains normal 
vi. Failed conservative treatment, including a reasonable trial of physical therapy, activity modification, pain medications, neck brace, and other modalities.

\section{Conservative treatment}

Conservative therapy was recommended to every subject, and subjects were told that surgery was to be undertaken only if non-operative therapy failed. Our goal was to optimize alignment with brace, to strengthen the neck, and to avoid injurious activities. Most patients were fitted with a neck brace (usually the Aspen Vista® Cervical Collar), directed to wear it for $23 \mathrm{~h}$ a day for 4 weeks, and given detailed instructions on the performance of isometric exercises to strengthen the neck. They were instructed to maintain good neck posture at all times and to avoid neck bending, prolonged sitting, driving, and any activities involving contact sports, deceleration, or strenuous activities which could harm the neck. Physical therapy was ordered, with the caveat that range of motion exercises and manipulation should be avoided. Several subjects with very severe symptoms had already undergone a protracted period of non-operative therapy and were not compelled to repeat the conservative therapy regimen. In several cases, the neck brace was discontinued because of pressure against the mandible, causing severe pain in the temporomandibular joint.

\section{Operative technique}

The surgical technique, described by Goel and Harms, was modified [3, 30]. The C1 screw entry points, measured on the pre-operative CT scan from the midpoint, were drilled and tapped toward the anterior tubercle of $\mathrm{C} 1$ as seen on sagittal view, angling approximately $8^{\circ}$ medially. At the $\mathrm{C} 2$ level, screws were angled medially $30^{\circ}$, and, superiorly, parallel to the cortex of the superior facet of C2. Twenty-fourmillimeter smooth shank screws were placed at $\mathrm{C} 1$, and fully threaded 24-mm screws at C2 (Solstice®, LifeSpine Inc., Huntley, IL), except in those cases where the large size of the vertebral artery foramen, or small pedicle, militated for a shorter screw. An intraoperative fluoroscopic-CT scan ensured correct screw placement. Bone marrow, harvested by aspiration from the iliac crest, was infused into a saline-soaked, tri-cortical, iliac crest allograft; the allograft was contoured precisely to fit the decorticated, posterior ring of $\mathrm{C} 1$, and the lamina and spinous process of $\mathrm{C} 2$ (Fig. 4a-d).

\section{Post-operative management}

Patients were encouraged to stand at the bedside on the evening of the surgery, and to ambulate on post-operative day 1 .
The wound drain was removed on post-operative day 2 or 3 . Intravenous opiate (dilaudid or morphine), administered by patient-controlled administration (PCA), was weaned off on post-op day 2; oral opiates and Ketorolac $₫ 10 \mathrm{mg}$ (every $6 \mathrm{~h}$ ) were given on the third day. Patients wore a neck brace for 1 month after surgery, and then started on physical therapy for posture, core strengthening, cardiovascular fitness, and isometric exercises of the neck. Subjects were asked to maintain strict neck posture. Range of motion exercises was discouraged in this cohort to avoid potential ligamentous injury to the lower cervical levels. Follow-up was conducted at 2 weeks, and at 3 months, at which time a CT of the cervical spine was performed.

\section{Statement of human and animal rights}

All procedures performed in studies involving human participants were carried out in accordance with the ethical standards of the institutional and/or national research committee in the USA, and with the 1964 Helsinki declaration and its later amendments or comparable ethical standards. Informed consent was obtained from all individual patients and participants included in the study.

\section{Results}

\section{Study subjects}

Included in the study were 20 subjects (4 males, 16 females), ages 18-54 years, average age 34 years at time of surgery from 11 different states in North America. The subjects

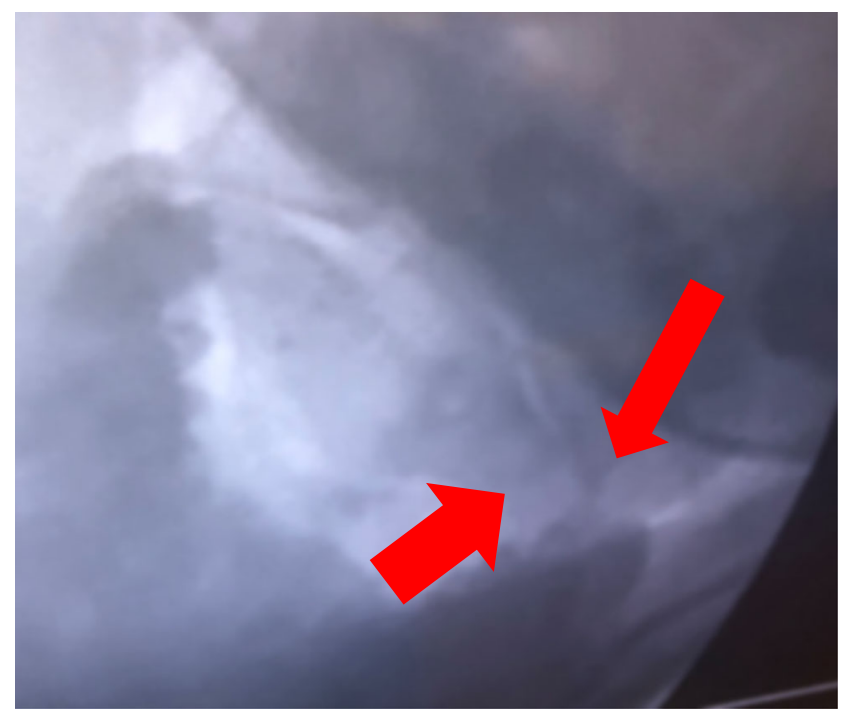

Fig. 3 Open mouth antero-posterior view of digital dynamic imaging of the cervical spine shows a pathological translation of $5 \mathrm{~mm}$ to the right (see arrows), which exceeds the normal reference range $(<2 \mathrm{~mm})$ 
Fig. 4 a Sagittal reconstruction of the cervical spine CT showing placement of the $\mathrm{C} 1-\mathrm{C} 2$ screws and connecting rods (Goel-Harms technique of C1-C2 stabilization). b CT mid-sagittal reconstruction showing the C1-C2 fusion. Note the allograft encompasses the posterior ring of $\mathrm{C} 1$ and tightly abuts the spinous process and lamina of C2. c Coronal view of CT showing graft placement between the posterior ring of $\mathrm{C} 1$ above and the spinous process and lamina of $\mathrm{C} 2$ below, and between the screws at $\mathrm{C} 1-\mathrm{C} 2$ bilaterally. d A 3D CT reconstruction of the upper cervical spine showing the $\mathrm{C} 1-\mathrm{C} 2$ fusion and stabilization from a posterior perspective.
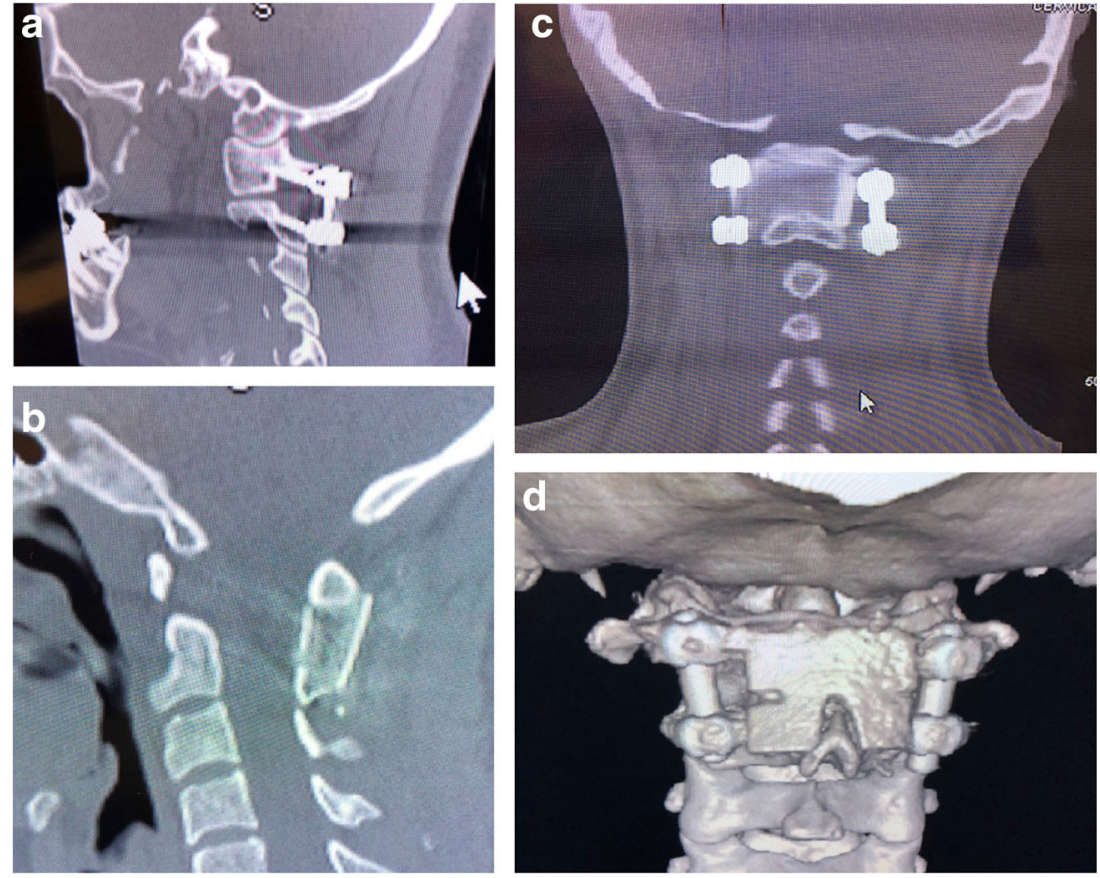

underwent atlanto-axial reduction, fusion, and stabilization between 2017 and 2018 by the senior authors (FH, RR).

\section{Neurological findings}

Four symptoms commonly occurred in this cohort: headaches in the distribution of the occipital nerves (unilateral or bilateral, exacerbated by looking up or down, and driving upon uneven surfaces): frequent syncopal or pre-syncopal episodes on a daily or weekly basis (the subjects reported learning to anticipate a syncopal episode, and undertaking immediate avoidance strategies), visual changes (including teichopsia, decreased peripheral, or "tunnel" vision; most subjects reported walking into door frames, benches, tables, or people), many reported "a brownout" or extreme blurring of vision, and finally, intermittent dysesthesias of the extremities. All subjects reported poor concentration and memory, nausea, and tinnitus.

Three physical findings were commonly present. First, moderate or severe tenderness to pressure over $\mathrm{C} 1$, which often provoked nausea. Second, hypoesthesia to pinprick over most of the cervical, thoracic, lumbar, and sacral dermatomes, in which the subject reported that the pin was pointed, but not painful. Proprioception and vibratory sensation were rarely impaired. Third, hyperreflexia, especially of the patellar tendons (12/20), except in those subjects with peripheral neuropathy due to B12 deficiency $(8 / 20)$ who demonstrated hyporeflexia. Less common were weakness $(9 / 20)$, dysdiadochokinesia (5/20), Romberg sign (6/20), and impairment of tandem gait (7/20).

\section{Radiological findings pre-operatively}

The average angle between $\mathrm{C} 1$ and $\mathrm{C} 2$ on full-neck rotation to each side was $42^{\circ}$ (Fig. 1a and b). Significant loss of facet overlap (that is, less than $20 \%$ facet overlap) was demonstrated in all subjects (less than 10\% in four, less than 5\% overlap in two) (Fig. 2). Several patients also underwent open mouth, antero-posterior views showing excessive translation on lateral tilt (exceeding $3.5 \mathrm{~mm}$ to left and/or right) (Fig. 3).

\section{The Karnofsky Performance score (KPS)}

Improvement in performance reached statistical significance ( $P=0.022$, with $50 \%$ of subjects returning to work (Fig. 5).

\section{Improvement in the Short Form Health Survey}

Patients reported statistically significant improvement in activities such as running, lifting $(P=0.01)$, bending, stooping $(P<0.05)$, and walking several hundred yards to a mile $(P=$ 0.02 ) (Table 1). The total mean (SD) SF-36 physical function raw score (which can range from 10 to a maximum of 30 ) improved from 16.6 (5.1) pre-surgery to 20.4 (5.3) postsurgery $(P=0.02)$.

\section{Symptoms showing significant improvement after surgery}

As displayed in Table 2, patients reported a statistically significant improvement in the frequency and severity of headaches (Figs. 8 and 9) and neck pain (Fig. 10), hand numbness, 
Fig. 5 Histograms comparing pre-operative and post-operative Karnofsky Performance scores shows a statistically significant improvement of performance $(P=0.02)$ after the $\mathrm{C} 1-\mathrm{C} 2$ fusion stabilization; most patients were able to return to work or school

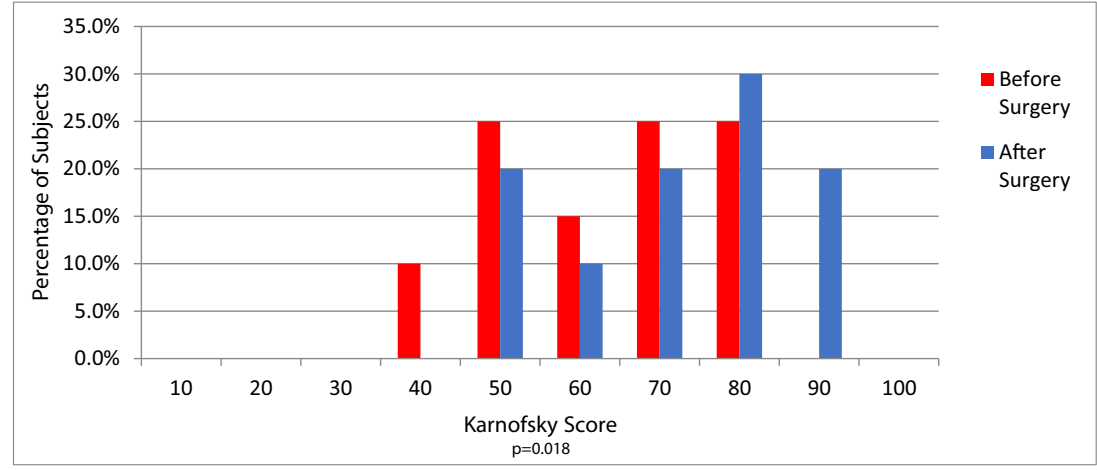

lower extremity numbness, arm weakness, syncope, and presyncope, and to a milder extent in joint pain, myalgias, nausea, anxiety, and depression. There was also improvement in the frequency of lightheadedness, vertigo, brain fog, and palpitations, and in the severity of exercise intolerance.

\section{Symptoms with no improvement}

There was no significant improvement in fatigue, memory, balance, swallowing/choking, leg weakness, or sexual difficulties (Table 3).

\section{Patient's Global Impression of Change}

Sixty-five percent of subjects reported an improvement as measured by the Global Clinical Impression of Change (Fig. 6). Thirty-five percent of subjects reported no significant overall improvement. Global pain (total body, joint, spine, head, viscera) was also assessed with the visual analog scale (VAS): one reported worse pain, 7 were unchanged, the remaining 12 were improved. The overall pre-operative VAS of global pain was $7 / 10$, and the post-operative global pain (VAS) was $6 / 10$ $(P=0.001)$.

\section{Patient satisfaction surveys}

Overall, $90 \%$ of patients indicated they would repeat the surgery given the same circumstances, and $10 \%$ would not repeat the surgery, citing the presence of continued comorbidities (Fig. 7a). Four of the 20 subjects $(20 \%)$ stated that the surgery did not help their overall quality of life (Fig. 7b).

\section{Post-operative fusion}

Eighteen fusions (18/20) were confirmed by CT. One subject chose not to undergo post-op CT, but had no complaints. One subject experienced trauma and returned with failed fusion; a second subject returned with a broken screw, but evidence of good fusion (see below).

Table 1 Comparison of SF-36 PF subscale pre- vs. post-surgery

\begin{tabular}{|c|c|c|c|c|c|c|}
\hline Limitation measure & $\begin{array}{l}\% \text { with limitation } \\
\text { pre-op }\end{array}$ & $\begin{array}{l}\% \text { with limitation } \\
\text { post-op }\end{array}$ & $\begin{array}{l}\% \text { with improvement } \\
\text { post-op* }\end{array}$ & $\begin{array}{l}\% \text { with worsening } \\
\text { post-op }^{\dagger}\end{array}$ & $\begin{array}{l}\% \text { with onset } \\
\text { post-op }\end{array}$ & $P$ value \\
\hline Vigorous activities (running, lifting, etc.) & $100 \%$ & $95 \%(19 / 20)$ & $45 \%(9 / 20)$ & $5 \%(1 / 20)$ & 0 & 0.01 \\
\hline $\begin{array}{l}\text { Moderate activities (vacuuming, } \\
\text { bowling, etc.) }\end{array}$ & $95 \%(19 / 20)$ & $80 \%(16 / 20)$ & $52.7 \%(10 / 19)$ & $5.3 \%(1 / 19)$ & $5 \%(1 / 20)$ & 0.14 \\
\hline Lifting or carrying groceries & $85 \%(17 / 20)$ & $65 \%(13 / 20)$ & $58.8 \%(10 / 17)$ & $11.8 \%(2 / 17)$ & $5 \%(1 / 20)$ & 0.11 \\
\hline Climbing several flights of stairs & $90 \%(18 / 20)$ & $83.3 \%(17 / 20)$ & $38.9 \%(7 / 18)$ & $5.6 \%(1 / 18)$ & $5 \%(1 / 20)$ & 0.10 \\
\hline Climbing one flight of stairs & $65 \%(13 / 20)$ & $60 \%(12 / 20)$ & $45 \%(9 / 20)$ & 0 & $30 \%(3 / 20)$ & 0.17 \\
\hline Bending, kneeling, stooping & $85 \%(17 / 20)$ & $75 \%(15 / 20)$ & $52.9 \%(9 / 17)$ & $17.6 \%(3 / 17)$ & $5 \%(1 / 20)$ & $<0.05$ \\
\hline Walking more than a mile & $90 \%(18 / 20)$ & $75 \%(15 / 20)$ & $47.1 \%(9 / 18)$ & $5.6 \%(1 / 18)$ & $5 \%(1 / 20)$ & 0.09 \\
\hline Walking several hundred yards & $75 \%(15 / 20)$ & $50 \%(10 / 20)$ & $66.7 \%(10 / 15)$ & $6.7 \%(1 / 15)$ & $5 \%(1 / 20)$ & 0.02 \\
\hline Walking 100 yards & $55 \%(11 / 20)$ & $35 \%(7 / 20)$ & $72.3 \%(8 / 11)$ & 0 & $5 \%(1 / 20)$ & 0.11 \\
\hline Bathing and dressing yourself & $60 \%(12 / 20)$ & $45 \%(9 / 20)$ & $58.3 \%(7 / 12)$ & 0 & $10 \%(2 / 20)$ & 0.18 \\
\hline
\end{tabular}

*Where present pre-op

${ }^{\dagger}$ For those participants who had presence of symptom/problem prior to surgery

*Wilcoxon signed-rank test 


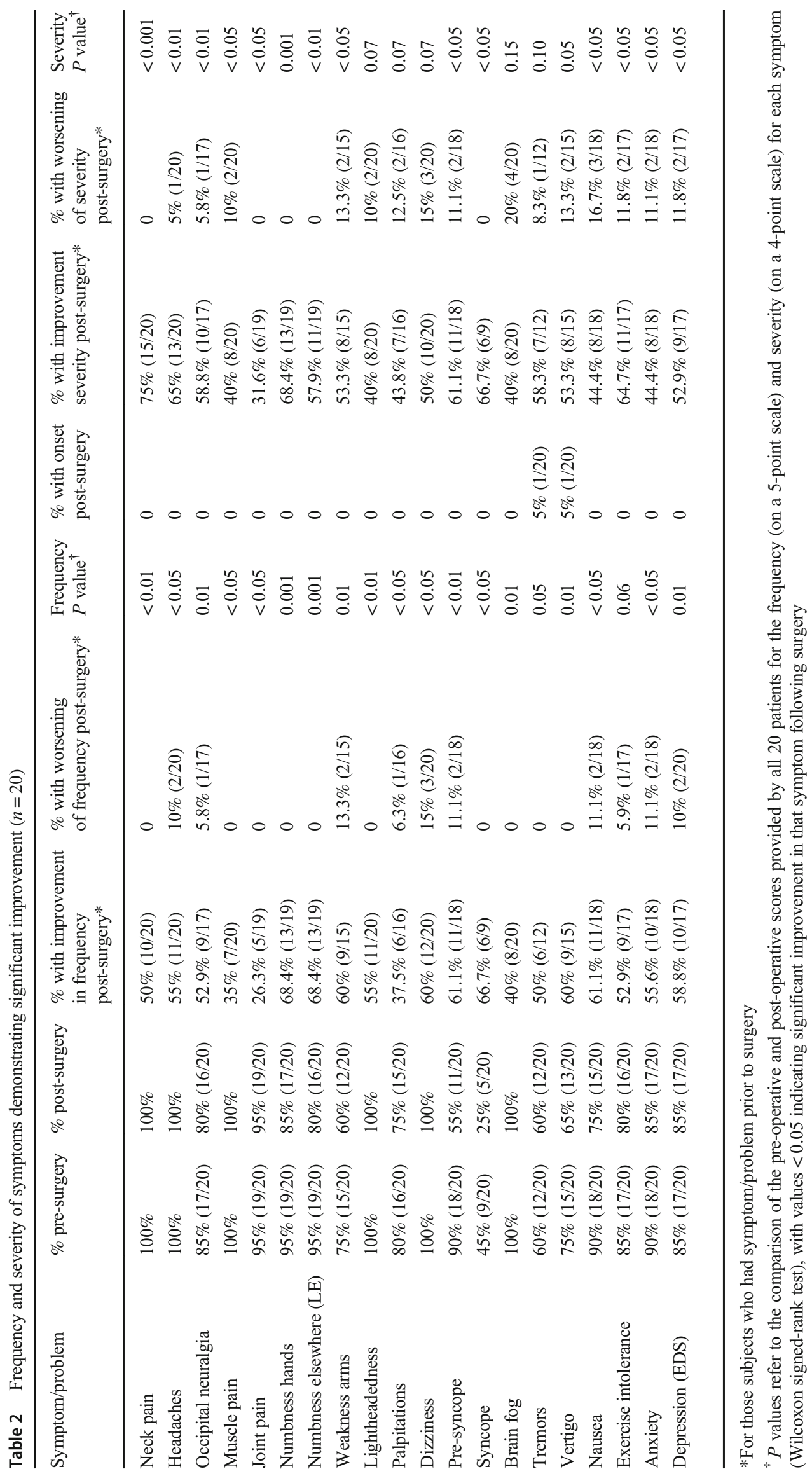




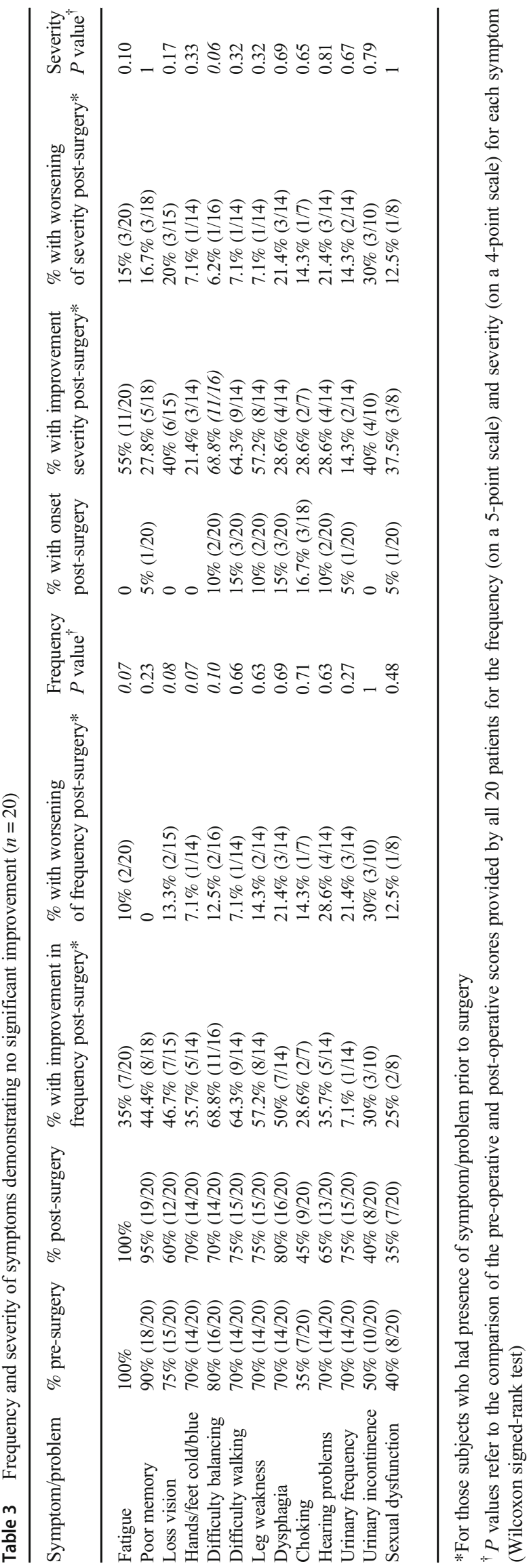

\section{Complications}

There were no peri-operative complications within the first month. One subject fell at 1 year and required revision of the C1-C2 fusion for broken graft. A second subject showed evidence of fusion at 6 months, but at 1 year, she demonstrated a broken $\mathrm{C} 2$ screw and exhibited clinical and radiological findings of cranio-cervical instability; she later required extension of the fusion to include the occiput (occiput-C2 fusion).

In the year after surgery, one subject underwent ICP monitoring for intracranial hypertension, one received a lumboperitoneal shunt, one occipital nerve neurolysis, and two were being evaluated for further lower level cervical spine pathology.

Every subject (20/20) suffered from ongoing orthostatic intolerance and at least one other comorbidity; these included mast cell activation syndrome, peripheral neuropathy, Chiari I malformation, transverse sinus stenosis, trigeminal neuralgia, epilepsy, cervical myelopathy, lower spinal CSF leak, SI joint dysfunction, Tarlov cyst syndrome, spina bifida occulta, fibromyalgia, digestive disorders (need J-tube/feeding tubes), esophageal dysmotility, gastroparesis, eosinophilic esophagitis, and interstitial cystitis. One subject was diagnosed with Gilbert syndrome, one with labyrinthitis, one Von Willebrand disease, and one parotid tumor.

\section{Discussion}

\section{Characteristic symptoms and signs of AAI}

In this study, AAI most commonly presented with four symptoms: severe headaches, syncope or pre-syncope, dysesthesias, and tunnel vision. In addition, most subjects reported nausea, tinnitus, and cognition issues. These symptoms should prompt consideration of AAI, especially in a patient with hypermobility issues.

Three findings were common in AAI: first, $\mathrm{C} 1-\mathrm{C} 2$ tenderness; second, ubiquitous hypoesthesia to pinprick; third, hyperreflexia, with the caveat that subjects with peripheral neuropathy did not have hyperreflexia. Weakness, dysdiadochokinesia, and altered tandem gate were often present, and not dissimilar to those described in the literature for AAI $[3,16,30,32,48]$.

\section{Radiologic diagnosis of AAI}

Alar ligament incompetence underlays AAI in this cohort, consistent with the literature $[38,42,50]$. The subluxations are Fielding's type 1, with anterior displacement (subluxation) of the facet on one side, and a normal atlanto-dental interval (ADI less than $3 \mathrm{~mm}$ ) (Fig. 2a and b), reducible, and bestfused posteriorly [26, 88] (Fig. 4a-d). 
Failure to diagnose AAI resides in the difficulty of recognizing rotary instability on standard $\mathrm{x}$-ray, CT, and MRI images [57]. The use of rotational CT to diagnose rotary subluxation was established with cadaveric studies, which demonstrated a mean rotation between atlas and axis of $31.1^{\circ}$, increasing to $35^{\circ}$ after contralateral rupture of the alar ligament [18]. In adults, there is vertebral artery obstruction at $40^{\circ}$ rotation. For the purposes of this study, the diagnosis of AAI was based upon an angular displacement between $\mathrm{C} 1$ and $\mathrm{C} 2$ $\geq 41^{\circ}$ as seen on CT axial views [18-20, 42, 44, 56, 74] (Figs. $1 \mathrm{~b}$ and $2 \mathrm{a}$ and $\mathrm{b}$ ).

Severe pain may limit the range of motion, in which case a rotation $\mathrm{CT}$ will be non-diagnostic; in these subjects, AAI can be alternatively demonstrated on lateral head tilt (Fig. 3). Lateral translation of more than $1.6-3 \mathrm{~mm}$ "offset" at the lateral margins of $\mathrm{C} 1$ on $\mathrm{C} 2$ is considered pathological [28, $46,47,84]$. The authors have used a translation of $\geq 3.5 \mathrm{~mm}$ of the lateral mass of $\mathrm{C} 1$ upon $\mathrm{C} 2$, as seen on open mouth views during lateral neck tilt, as the pathological threshold in the demonstration of AAI [50] (Fig. 3).

Other techniques assess instability on the basis of the offset of the odontoid between the lateral masses; asymmetric distance between the lateral mass and dens is a common finding [28].

Loss of facet overlap $(<20 \%)$ is an indicator of rotatory subluxation. A 3D CT could also be helpful to demonstrate subluxation [27] (Fig. 2a). Cineroentgenography is helpful in diagnosing rotary subluxation [90].

Diagnosis of AAI may be made on the basis of compromise of the vertebral arteries, anomalous joints, and retro-odontoid pannus [32, 48, 51, 97]. Ligamentous disruption of the alar and odontoid ligaments is associated with increased signal intensity on high-resolution proton density-weighted MRI $[58,81]$.

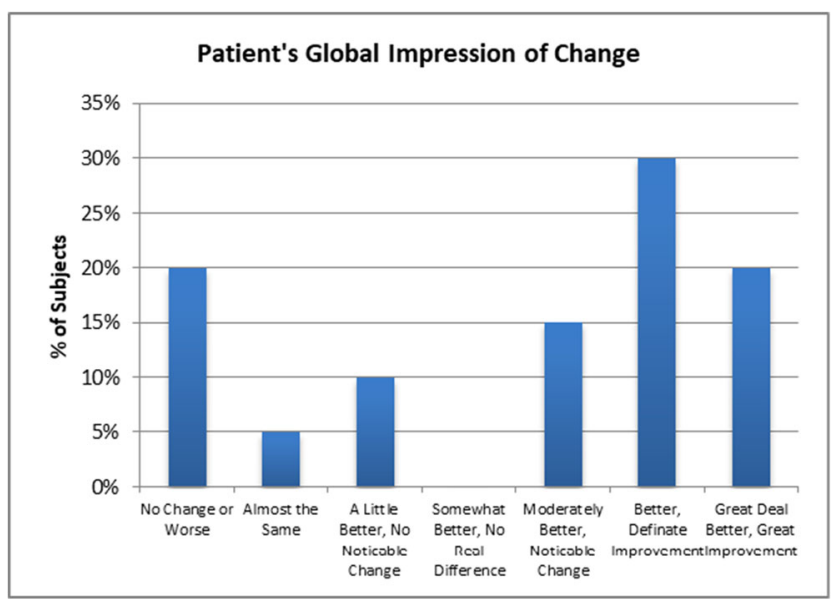

Fig. 6 Patient's Global Impression of Change; graph histograms show that $65 \%$ of subjects reported improvement, and $35 \%$ of subjects reported no significant improvement of overall symptoms. (The failure of many to improve was thought in part to be the result of the many comorbid conditions experienced by the subjects)

\section{Indications for AAI surgery}

In the general population, fusion is indicated when nonoperative therapy fails to maintain normal correction and ensure stability, to maintain correction in the presence of central nervous system compromise - even if transient - and to maintain a normal C1-C2 relationship [26]. Before recommending surgery for AAI in the hereditary connective tissue population, the authors would add the requirements, with some exceptions, of severe neck or suboccipital pain (usually $\geq 7 / 10$ ), appropriate neurological symptoms and findings, and congruent radiological findings, with the caveat that dynamic imaging is usually necessary to demonstrate ligament incompetence [42]. Moreover, atlanto-axial fusion should be considered the last option, only after the patient has undergone a reasonable trial of non-operative treatments.

\section{AAI surgery}

The authors utilized the Goel-Harms technique, utilizing a C1 lateral mass screw, $\mathrm{C} 2$ pedicle screw fixation, and rods to stabilize the atlanto-axial joint (Fig. 4a-d). This technique is biomechanically reliable, precise, permissive of reduction, and adaptable to most anatomical variations. Moreover, this construct can be readily extended to the occiput or to the subaxial spine at a later date $[1,9,14,15,31,39,95]$.
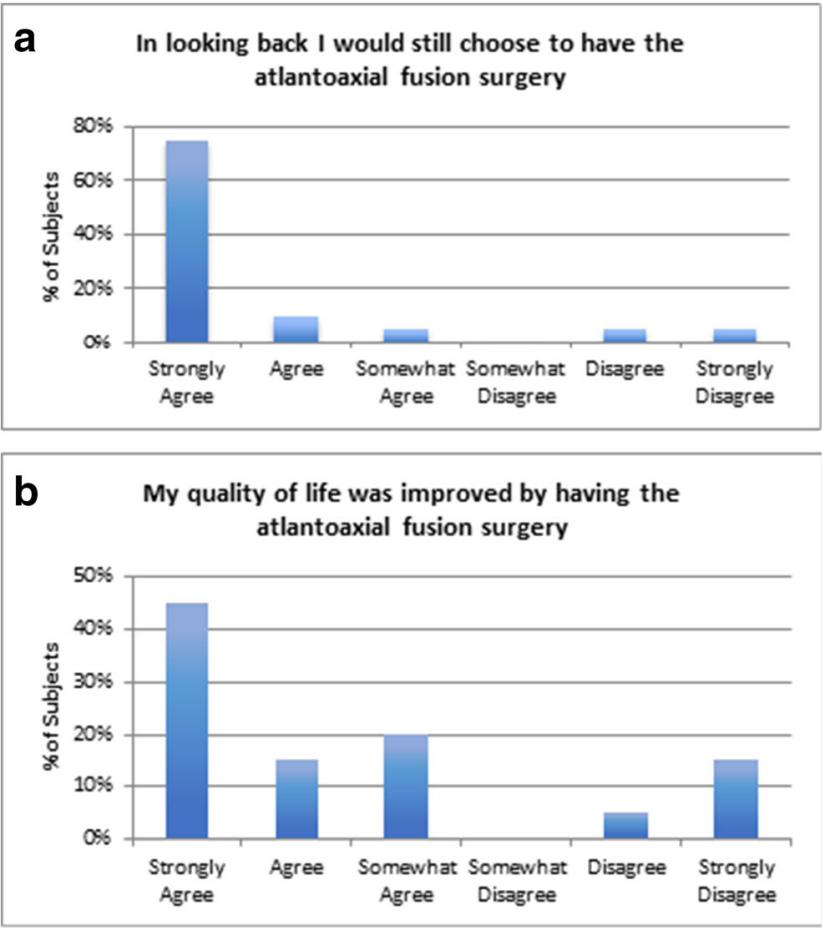

Fig. 7 a Histogram showing patient assessment of surgery; in looking back, $90 \%$ of subjects would repeat the surgery given the same circumstances, and $10 \%$ ( 2 patients) would not repeat the surgery. b Histograms of patient assessment of quality of life, showing that $80 \%$ enjoyed an improved quality of life, whereas $20 \%$ did not 
Surgery in this cohort of EDS subjects was more difficult for three reasons. First, the bone quality, though adequate to proceed with fusion, was generally osteopenic. Serum testing showed that many subjects were deficient in vitamin $\mathrm{D}$, in which case they were prescribed large doses of vitamin D (®Ergocalciferol, 50,000 $\mu$ weekly). Subjects with osteoporosis were prescribed calcitonin nasal spray (1 puff daily) and calcium citrate. Second, the frequent comorbidities inherent to EDS required a more comprehensive medical management. Third, bone structures were smaller than average, requiring very accurate placement of screws. Thus, careful study of the CT scan and MRI is necessary prior to placing screws. The hereditary connective tissue disorders are associated with less robust bone anatomy, and a vertebral artery foramen closer to midline. Many fall in the category of patients in whom the pedicles of $\mathrm{C} 2$ are very narrow pose greater risk for neurovascular complications with pedicle screw placement [72]. It may be necessary to place a shorter pedicle screw on the side of the dominant vertebral artery.

The authors have identified common pitfalls related to fusion for AAI. First, a small C1 sagittal diameter may predispose to iatrogenic canal stenosis upon placement of the graft; this is obviated by concave sculpting on the underside of the graft. Second, a diminutive posterior ring of $\mathrm{C} 1$ has little cancellous bone and requires very precise fashioning of the bone graft to achieve fusion. Third, the $\mathrm{C} 1$ lateral mass screw should be angled toward the lower third of the anterior tubercle (as seen on sagittal view), to ensure that the screw does not transgress the atlanto-condylar joint. Fourth, segmentation failure between occiput and C1-the HOX-D3 homeotic transformation-requires fusion of the occiput to $\mathrm{C} 2$. Fifth, a Klippel-Feil anomaly at the C2-C3 level is associated with a small $\mathrm{C} 2$ pedicle, requiring instrumentation to include $\mathrm{C} 3$. Fifth, an overly lordotic C1-C2 segment results in a compensatory iatrogenic, subaxial kyphosis, swan neck deformity, or subaxial subluxation post-operatively; conversely, C1-C2 kyphosis results in subaxial hyperlordosis [64].

Anatomical reduction to restore optimal alignment of C1$\mathrm{C} 2$ is necessary. Incomplete reduction risks injury to the vertebral arteries [60]. The 7\% incidence of the posterior inferior cerebellar artery arising in the extra-dural location, and the $2.3 \%$ incidence of other anomalies, such as the pro-atlantal variants, should be kept in mind [85]. The ponticulus posticus, or Kimmerle anomaly, is common-19.3\% in one seriesand associated with a higher risk of VA injury [45]. Abnormal alignment of $\mathrm{C} 1$ and $\mathrm{C} 2$ may narrow the spinal canal and obstruct cerebrospinal fluid flow [65].

\section{Neurological outcomes after fusion stabilization}

Neurological symptoms improved after the C1-C2 fusion stabilization. Improvement reached statistical significance in neck pain and headaches. The surprising improvement in joint and muscle pain is ascribed to improved neuromuscular control. There was statistically significant improvement in nausea, dizziness, lightheadedness, anxiety, bowel incontinence, and palpitations. The authors postulate that the nausea and vertigo in this population may sometimes result from intermittent compromise of the vertebral artery with transient ischemia of the peripheral labyrinth. Intermittent ischemia can result from abnormal $\mathrm{C} 1-\mathrm{C} 2$ rotation or alignment, occipital bone anomaly, hypertrophy of the atlanto-occipital membrane, tightness of the paravertebral muscles, or constriction by fibrous bands $[12,54,86]$.

The improvement in tremors was borderline. There was highly statistically significant improvement in pre-syncope, syncope, and exercise intolerance (Table 2). The improvement in syncope and pre-syncope is presumably due to elimination of mechanical deformative stress of the upper spinal cord or brainstem [35, 42, 43, 69]. Modest improvement-though not statistically significant - was seen in imbalance, vision problems, hands and feet turning cold/blue, and fatigue (Table 3). Symptoms related to hearing, swallowing, and breathing were not improved, nor was leg strength.

The patient satisfaction surveys were generally positive. However, two patients reported dissatisfaction with the surgery and no improvement in quality of life. Given the nature of the survey, the reason for dissatisfaction was not apparent, though the large number of comorbid conditions may have been responsible in part for ongoing disability.

\section{Behavioral symptoms}

There was a surprising pre-operative incidence of depression $(17 / 20)$ and anxiety $(18 / 20)$. Highly statistically significant improvement in anxiety and depression followed stabilization. These findings suggest a salutary effect upon the brainstem with respect to the upward transmission to hypothalamus, amyygdala, medial forebrain, temporal, and limbic lobes. Physiological stressors have been shown to activate $\mathrm{C} 1$ neurons, and result in global sympatho-excitation [37]. It is reasonable, moreover, to expect that alleviation of the burden of disability, pain, and illness would decrease anxiety and depression.

\section{The effect of C1-C2 fusion on headache and pain}

The improvement of headache (Fig. 8) paralleled the improvement of occipital neuralgia (Fig. 9), suggesting that a significant component of headache results from the greater occipital nerves. Unlike all other cervical roots, the $\mathrm{C} 2$ roots exit between the laminae and are more subject to the chronic trauma inherent in highly mobile segments. The improvement in neck pain (Fig. 10) presumably is the logical consequence of stabilization of the unstable motion segment. The less impressive improvement in global pain evident in the global visual analog 
scale and the Global Impression of Change reflects the significant amount of pain these subjects with EDS were experiencing elsewhere throughout the body.

\section{Complications of C1-C2 fixation and fusion}

Though there were no apparent peri-operative complications, it was necessary to revise the fusions in 2 subjects (10\%) over 12 months after surgery. In one case, the necessary revision was due to the patient falling. Prior to the fall, the allograft exhibited early bone growth on CT, the appearance of which was lost after the fall. This occurrence draws attention to the slow mineralization and remodeling of the allograft fusion, which typically requires at least 12 months in this patient population. In a second subject, bone fusion between $\mathrm{C} 1$ and $\mathrm{C} 2$ was demonstrated on $\mathrm{CT}$ at the 6-month post-operative visit, but a broken screw at $\mathrm{C} 1$ was noted on $\mathrm{CT}$ at 12 months, suggesting that even in the presence of a demonstrably successful fusion, the mechanical stresses upon the $\mathrm{C} 1$ level are substantial and capable of causing metal fatigue and fracture, underscoring the potential of increased magnitude of deformative stress at the cranio-cervical junction in this population.

Fusion failure in this patient population is probably higher due to osteopenia and small bone anatomy, and consistent with the higher rate of failed posterior fusion in patients with rotational instability [13].

Larger studies of C1-C2 fusion have described suboccipital numbness (16.8 to $50 \%$ ) which usually subsides over several months: failed fusion $(0.2 \%)$; dural tears $(0.3 \%)$; screw breakout at the atlanto-axial complex $(0.4 \%)$; screw fracture $(0.8 \%)$; infection $(0.5 \%)$; and suboccipital neuralgia $(0.1 \%)$ [94].

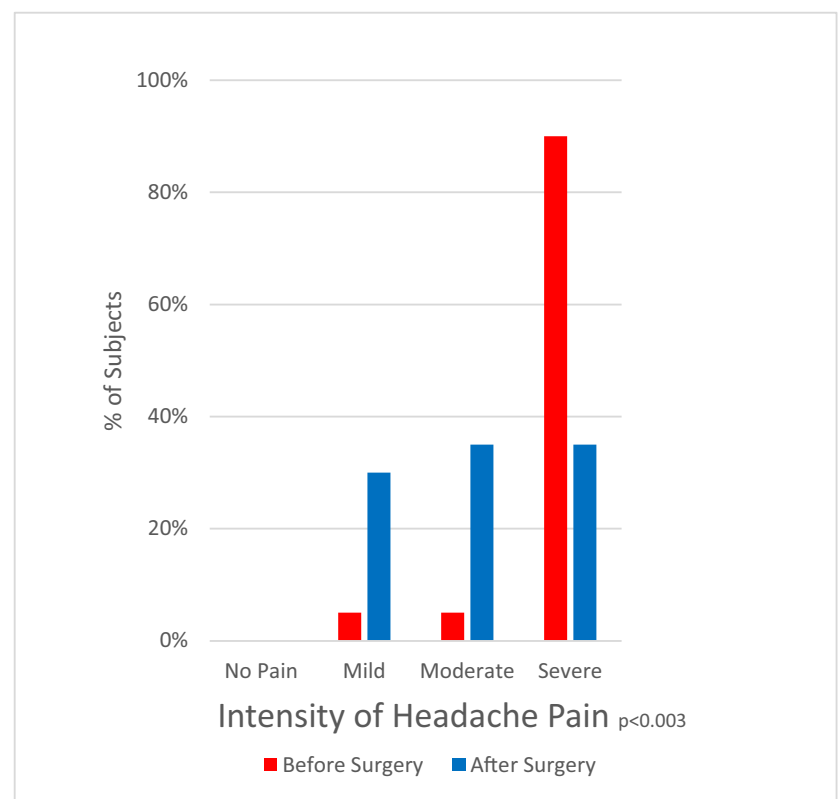

Fig. 8 Histograms of intensity of headache show a statistically significant improvement in pain intensity $(P=0.03)$

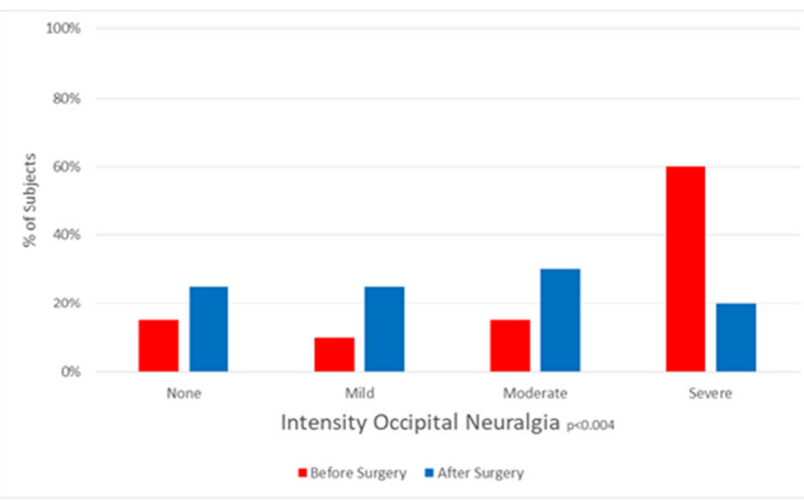

Fig. 9 Histograms of intensity of pre-operative and post-operative occipital neuralgia show a statistically significant improvement of neuralgia intensity $(P<0.01)$

The Goel-Harms technique is associated with a lesser morbidity than transarticular $\mathrm{C} 1-\mathrm{C} 2$ fixation technique. In the latter, Madawi reported screw malposition in 15/61, failed fusion $8 / 61$, screw breakage in $5 / 61$, and cranial nerve injury in $1 / 61$ [60]. The risk of compromise of the vertebral artery is 1.2 to $8.2 \%$ per subject undergoing pedicle screw fixation, with a risk of neurological deficit 0.2 to $3.7 \%$, and death $0.1 \%$ [22, $60,73,94,96]$.

There is an increased risk of vascular injury associated with the connective tissue disorders. Paramore reported a high riding $\mathrm{C} 2$ transverse foramen in $18 \%$ of patients [75]. A high riding vertebral artery was present in 50 to $70 \%$ of patients with Down syndrome, rheumatoid arthritis, basilar invagination, Klippel-Feil syndrome, and congenital skeletal anomalies [11]. Madawi found that the pedicle anatomy precluded safe screw placement in $20 \%$ of patients [60]. Moreover, the risk of vertebral artery injury and stroke is increased when a dominant left vertebral artery-which occurs in $50 \%$ of patients - is associated with a contralateral hypoplastic vertebral artery, which occurs in 1.9 to $11.6 \%$ of patients [52].

The authors strongly endorse careful study of thin-slice axial and sagittal computerized tomography scans of the C1C2 complex, to select screw length and trajectory $[11,17]$.

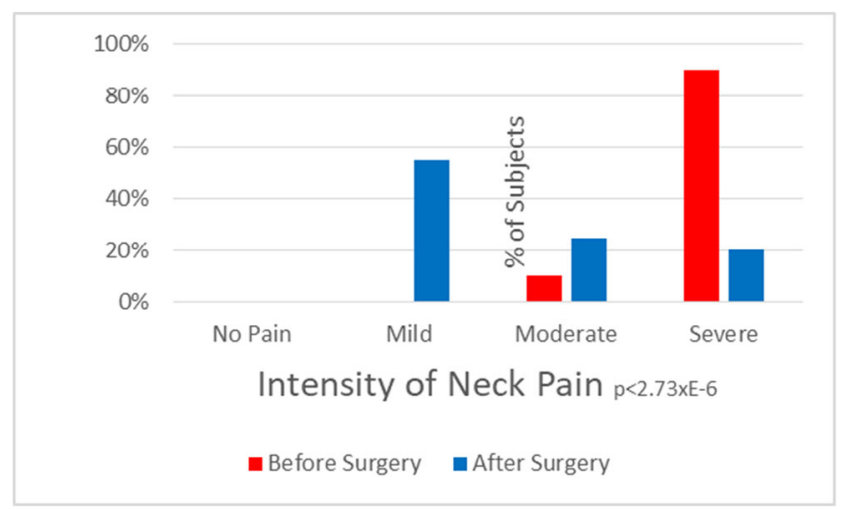

Fig. 10 Histograms of pre-operative and post-operative intensity of neck pain show a statistically significant improvement in neck pain intensity post-operatively $(P<0.0001)$ 


\section{Etiology of AAI}

The atlanto-axial junction (AAJ) is the most mobile joint of the body. Held together by ligaments that allow a great degree of freedom of rotation, the AAJ is responsible for $50 \%$ of all neck rotation, $5^{\circ}$ of lateral tilt, and 10 to $20^{\circ}$ of flexion/extension [91]. Weakness of the muscles and ligaments, hormonal changes, infection, immunological problems, and congenital dysmorphism may contribute to the overall mechanical dysfunction at the C1-C2 motion segment. An intrinsic defect in collagen fibers results in ligamentous laxity, such that AAI may be the product of chronic trauma "superimposed on congenitally weakened ligaments" such as in Down and Ehlers-Danlos syndromes $[41,42,61,77]$. AAI was found in 3 of the 4 subjects with EDS-vascular type [38, 48, 78].

The mechanical properties of the $\mathrm{C} 1-\mathrm{C} 2$ motion segment are primarily determined by transverse and alar ligaments, although finite element analysis suggests importance of the tectorial membrane and atlanto-condylar ligaments [83, 87, 93]. The tectorial membrane and accessory atlantoaxial ligaments contribute to passive restraints of the atlanto-axial junction [99]. Incompetence of the cruciform ligament in restraining anterior subluxation of the $\mathrm{C} 1$ ring underlies AAI in rheumatoid arthritis and Down syndrome [21, 24, 25, 68, 89]. However, the subjects in this cohort, as in Fielding's series of 17 subjects with rotary type I AAI, are characterized by alar ligament incompetence. The alar ligament attaches from the odontoid to the occiput and $\mathrm{C} 1$ ring, restraining rotation, and lateral tilting [20].

The AAJ is ill-equipped to handle the required multi-axial movements in the presence of ligamentous laxity or disruption. The alar ligament consists chiefly of inelastic collagen fibers, and can be irreversibly stretched after trauma, potentially leading to chronic occult hypermobility of the craniocervical junction. The alar ligaments are often injured in motor vehicle collisions and implicated in whiplash-associated disorders. Moreover, the long slender neck in women with hEDS is more vulnerable in flexion extension injury [4, 6, 87]. Failure of the alar ligament allows a $30 \%$ increased rotation to the opposite side [19].

In the adult, there is normally substantially less than $40^{\circ}$ of rotation at the $\mathrm{C} 1-\mathrm{C} 2$ motion segment $[62,74$, 101]. At $35^{\circ}$ of rotation of $\mathrm{C} 1$ upon $\mathrm{C} 2$, there is stretching and kinking of the contralateral vertebral artery [80], and between 40 and $45^{\circ}$, both vertebral arteries become fully occluded [67]. Extreme rotation of the cervical spine may cause injury to the vertebral arteries, with resulting cerebellar or brainstem stroke, and death [79]. It should be emphasized that the reference range of $\mathrm{C} 1-\mathrm{C} 2$ angular measurements are not established in children, in whom hypermobility is more prevalent.
Motor delay, headache associated with "connective tissue pathological relaxation" and quadriparesis have been attributed to ligamentous laxity and instability at the atlanto-occipital and atlanto-axial joints $[49,55,71]$. This may in part be explained by the decreased canal diameter and increased risk of spinal cord compression with increased $\mathrm{C} 1-\mathrm{C} 2$ angulation. With C1-C2 rotation, before the point of dislocation, $39 \%$ of subjects exhibit a spinal canal diameter of $1 \mathrm{~cm}$ [65]. A canal diameter less than $14 \mathrm{~mm}$ predicts both the development and severity of weakness, and should prompt consideration of surgical intervention $[8,53,100]$. Moreover, the small canal diameter that occurs with rotary subluxation causes obstruction of cerebrospinal fluid flow, precipitating headache and neurological deficits [2, 36, 59, 69, 92].

If the atlanto-axial motion segment becomes unstable and sagittal balance is compromised, compensatory subaxial deformity may occur. Atlanto-axial subluxation may decrease lordosis at the $\mathrm{C} 1-\mathrm{C} 2$ segment, such that the cervical spine compensates with increased lordosis to maintain balance [76, 98].

\section{Limitations}

The study was retrospective and limited to a cohort of 20 surgical subjects. Several candidates were excluded because of other concurrent surgeries. There was no control for placebo effect. Though an independent nurse collected the data, there may have been patient recall bias or a tendency to give positive answers. The length of the questionnaires delayed the data return; several subjects did not complete and return the data, and it was necessary to enlist sequential subjects. Comorbid conditions profoundly impacted the majority of subjects and probably influenced the outcome metrics.

\section{Conclusion}

A syndrome of severe occipital headache, syncope or pre-syncope, vision changes (especially impaired peripheral vision), dysesthesias of the extremities, hyperreflexia, and decreased pinprick sensation should prompt consideration of AAI. The diagnosis of rotary AAI (Fielding type 1) is difficult and requires directed workup, including dynamic imaging. Patient satisfaction is high, and there is significant improvement of neurological symptoms associated with appropriate reduction and $\mathrm{C} 1-\mathrm{C} 2$ stabilization.

Acknowledgments The authors are grateful to Betsy Graves Henderson, for her superb technical assistance in manuscript editing, preparation, and submission.

Funding information Fraser Henderson Sr. is a consultant for Life Spine, Inc. (Huntley, IL). 
Compliance with ethical standards All procedures performed in studies involving human participants were carried out in accordance with the ethical standards of the institutional and/or national research committee in the USA, and with the 1964 Helsinki declaration and its later amendments or comparable ethical standards. Informed consent was obtained from all individual patients and participants included in the study.

Open Access This article is licensed under a Creative Commons Attribution 4.0 International License, which permits use, sharing, adaptation, distribution and reproduction in any medium or format, as long as you give appropriate credit to the original author(s) and the source, provide a link to the Creative Commons licence, and indicate if changes were made. The images or other third party material in this article are included in the article's Creative Commons licence, unless indicated otherwise in a credit line to the material. If material is not included in the article's Creative Commons licence and your intended use is not permitted by statutory regulation or exceeds the permitted use, you will need to obtain permission directly from the copyright holder. To view a copy of this licence, visit http://creativecommons.org/licenses/by/4.0/.

\section{References}

1. Abumi K, Itoh H, Taneichi H, Kaneda K (1994) Transpedicular screw fixation for traumatic lesions of the middle and lower cervical spine: description of the techniques and preliminary report. J Spinal Disord 7:19-28. https://doi.org/10.1097/00002517199407010-00003

2. Andeweg J (1989) Intracranial venous pressures, hydrocephalus and effects of cerebrospinal fluid shunts. Childs Nerv Syst 5:318323. https://doi.org/10.1007/bf00274522

3. Aryan HE, Newman CB, Nottmeier EW, Acosta FL Jr, Wang VY, Ames CP (2008) Stabilization of the atlantoaxial complex via C-1 lateral mass and $\mathrm{C}-2$ pedicle screw fixation in a multicenter clinical experience in 102 patients: modification of the Harms and Goel techniques. J Neurosurg Spine 8:222-229. https://doi.org/ $10.3171 /$ spi/2008/8/3/222

4. Aspinall W (1990) Clinical testing for the craniovertebral hypermobility syndrome. J Orthop Sports Phys Ther 12:47-54. https:// doi.org/10.2519/jospt.1990.12.2.47

5. Batzdorf U (2014) Consensus statement. In: Batzdorf U, Henderson F, Rigamonti D (eds) Co-morbidities that complicate the treatment and outcomes of Chiari malformation. Lulu, pp $118-122$

6. Beighton P (1993) The Ehlers-Danlos syndromes. In: Beighton P (ed) McKusick's heritable disorders of connective tissue. Mosby Year Book, St. Louis, pp 189-251

7. Beighton P, Craig J (1973) Atlanto-axial subluxation in the Morquio syndrome. Report of a case. J Bone Joint Surg Br 55: 478-481

8. Boden SD, Dodge LD, Bohlman HH, Rechtine GR (1993) Rheumatoid arthritis of the cervical spine. A long-term analysis with predictors of paralysis and recovery. J Bone Joint Surg Am 75:1282-1297. https://doi.org/10.2106/00004623-19930900000004

9. Bransford RJ, Lee MJ, Reis A (2011) Posterior fixation of the upper cervical spine: contemporary techniques. J Am Acad Orthop Surg 19:63-71. https://doi.org/10.5435/00124635201102000-00001

10. Brockmeyer DL, Brockmeyer MM, Bragg T (2011) Atlantal hemi-rings and craniocervical instability: identification, clinical characteristics, and management. J Neurosurg Pediatr 8:357362. https://doi.org/10.3171/2011.7.Peds1138

11. Chang CC, Huang WC, Tu TH, Chang PY, Fay LY, Wu JC, Cheng H (2018) Differences in fixation strength among constructs of atlantoaxial fixation. J Neurosurg Spine 30:52-59. https://doi. org/10.3171/2018.6.spine171390

12. Choi K, Kim J, Kim J, Kim M (2013) Rotational vertebral artery occlusion mechanisms and long-term outcome. Stroke 44:18171824

13. Coyne TJ, Fehlings MG, Wallace MC, Bernstein M, Tator CH (1995) C1-C2 posterior cervical fusion: long-term evaluation of results and efficacy. Neurosurgery 37:688-692; discussion 692683. https://doi.org/10.1227/00006123-199510000-00012

14. De Iure F, Donthineni R, Boriani S (2009) Outcomes of C1 and C2 posterior screw fixation for upper cervical spine fusion. Eur Spine J 18(Suppl 1):2-6. https://doi.org/10.1007/s00586-0090981-1

15. Deen HG, Birch BD, Wharen RE, Reimer R (2003) Lateral mass screw-rod fixation of the cervical spine: a prospective clinical series with 1-year follow-up. Spine J 3:489-495

16. Dickman CA, Sonntag VK (1998) Posterior C1-C2 transarticular screw fixation for atlantoaxial arthrodesis. Neurosurgery 43:275280 discussion 280-271

17. Dull ST, Toselli RM (1995) Preoperative oblique axial computed tomographic imaging for $\mathrm{C} 1-\mathrm{C} 2$ transarticular screw fixation: technical note. Neurosurgery 37:150-151; discussion 151-152. https://doi.org/10.1227/00006123-199507000-00026

18. Dvorak J, Hayek J, Zehnder R (1987) CT-functional diagnostics of the rotatory instability of the upper cervical spine. Part 2. An evaluation on healthy adults and patients with suspected instability. Spine 12:726-731

19. Dvorak J, Panjabi M, Gerber M, Wichmann W (1987) CTfunctional diagnostics of the rotatory instability of upper cervical spine. 1. An experimental study on cadavers. Spine 12:197-205. https://doi.org/10.1097/00007632-198704000-00001

20. Dvorak J, Panjabi MM (1987) Functional anatomy of the alar ligaments. Spine 12:183-189. https://doi.org/10.1097/00007632198703000-00016

21. El-Khouri M, Mourao MA, Tobo A, Battistella LR, Herrero CF, Riberto M (2014) Prevalence of atlanto-occipital and atlantoaxial instability in adults with Down syndrome. World Neurosurg 82: 215-218. https://doi.org/10.1016/j.wneu.2014.02.006

22. Elliott RE, Tanweer O, Boah A, Morsi A, Ma T, Frempong-Boadu A, Smith ML (2014) Outcome comparison of atlantoaxial fusion with transarticular screws and screw-rod constructs: meta-analysis and review of literature. J Spinal Disord Tech 27:11-28. https:// doi.org/10.1097/BSD.0b013e318277da19

23. Fehlings MG, Cooper P, Errico TJ - Rheumatoid arthritis of the cervical spine, neurosurgical topics: degenerative disease of the cervical spine Y1-1992. - AANS M1 - Journal Article:- 125-139

24. Fehlings MG, Cooper P, Errico TJ (1992) Rheumatoid arthritis of the cervical spine, neurosurgical topics: degenerative disease of the cervical spine. AANS M1 - Journal Article:125-139

25. Fielding JW, Cochran G, Lawsing JF 3rd, Hohl M (1974) Tears of the transverse ligament of the atlas. A clinical and biomechanical study. J Bone Joint Surg Am 56:1683-1691

26. Fielding JW, Hawkins RJ (1977) Atlanto-axial rotatory fixation. (Fixed rotatory subluxation of the atlanto-axial joint). J Bone Joint Surg Am 59:37-44

27. Fielding JW, Stillwell WT, Chynn KY, Spyropoulos EC (1978) Use of computed tomography for the diagnosis of atlanto-axial rotatory fixation. A case report. J Bone Joint Surg Am 60:11021104

28. Fujiwara S, Tokunaga D, Oda R, Toyama S, Imai K, Doi A, Kubo $\mathrm{T}$ (2010) Dynamic close-mouth view radiograph method for the diagnosis of lateral dynamic instability of the atlantoaxial joint. 
Clin Imaging 34:375-378. https://doi.org/10.1016/j.clinimag. 2009.08.027

29. Gluf WM, Brockmeyer DL (2005) Atlantoaxial transarticular screw fixation: a review of surgical indications, fusion rate, complications, and lessons learned in 67 pediatric patients. J Neurosurg Spine 2:164-169. https://doi.org/10.3171/spi.2005.2. 2.0164

30. Goel A, Desai KI, Muzumdar DP (2002) Atlantoaxial fixation using plate and screw method: a report of 160 treated patients. Neurosurgery 51:1351-1356 discussion 1356-1357

31. Goel A, Laheri V (1994) Plate and screw fixation for atlanto-axial subluxation. Acta Neurochir 129:47-53. https://doi.org/10.1007/ BF01400872

32. Goel A, Phalke U, Cacciola F, Muzumdar D (2004) Atlantoaxial instability and retroodontoid mass-two case reports. Neurol Med Chir 44:603-606. https://doi.org/10.2176/nmc.44.603

33. Goel A, Shah A (2011) Atlantoaxial facet locking: treatment by facet manipulation and fixation. Experience in 14 cases. $\mathrm{J}$ Neurosurg Spine 14:3-9. https://doi.org/10.3171/2010.9. spine 1010

34. Goldman A (1988) Collagen disease, epiphyseal dysplasia, and related conditions. Diagn Treat Bone Joint Dis:3374-3441

35. Grabb PA, Mapstone TB, Oakes WJ (1999) Ventral brain stem compression in pediatric and young adult patients with Chiari I malformations. Neurosurgery 44:520-527 discussion 527-528

36. Guyenet PG (2006) The sympathetic control of blood pressure. Nat Rev Neurosci 7:335-346. https://doi.org/10.1038/nrn1902

37. Guyenet PG, Stornetta RL, Bochorishvili G, DePuy SD, Burke PGR, Abbott SBG (2013) C1 neurons: the body's EMTs. Am J Phys Regul Integr Comp Phys 305:R187-R204. https://doi.org/ 10.1152/ajpregu.00054.2013

38. Halko GJ, Cobb R, Abeles M (1995) Patients with type IV EhlersDanlos syndrome may be predisposed to atlantoaxial subluxation. J Rheumatol 22:2152-2155

39. Harms J, Melcher RP (2001) Posterior C1-C2 fusion with polyaxial screw and rod fixation. Spine 26:2467-2471. https:// doi.org/10.1097/00007632-200111150-00014

40. Healey D, Letts M, Jarvis JG (2002) Cervical spine instability in children with Goldenhar's syndrome. Can J Surg 45:341-344

41. Hedequist D, Bekelis K, Emans J, Proctor MR (2010) Single stage reduction and stabilization of basilar invagination after failed prior fusion surgery in children with Down's syndrome. Spine 35: E128-E133. https://doi.org/10.1097/BRS.0b013e3181bad0c2

42. Henderson FC Sr, Austin C, Benzel E, Bolognese P, Ellenbogen R, Francomano CA, Ireton C, Klinge P, Koby M, Long D, Patel S, Singman EL, Voermans NC (2017) Neurological and spinal manifestations of the Ehlers-Danlos syndromes. Am J Med Genet C: Semin Med Genet 175:195-211. https://doi.org/10.1002/ajmg.c. 31549

43. Henderson FC, Wilson WA, Mott S, Mark A, Schmidt K, Berry JK, Vaccaro A, Benzel E (2010) Deformative stress associated with an abnormal clivo-axial angle: a finite element analysis. Surg Neurol Int 1. doi:https://doi.org/10.4103/2152-7806.66461

44. Henderson Sr F, Henderson Jr F (2017) Diagnosis of atlantoaxial instability requires clinical suspicion to drive the radiological investigation. J Spine 6. doi:https://doi.org/10.4172/2165-7939. 1000364

45. Hong JT, Lee SW, Son BC, Sung JH, Yang SH, Kim IS, Park CK (2008) Analysis of anatomical variations of bone and vascular structures around the posterior atlantal arch using three- dimensional computed tomography angiography. J Neurosurg Spine 8:230-236. https://doi.org/10.3171/spi/2008/8/3/230

46. Howe J (1990) Upper cervical check ligaments damage. In: Jaeger SPD (ed) Case studies in chiropractic radiology. Aspen Publishers, New York, pp 39-44

47. Ishii K, Chiba K, Maruiwa H, Nakamura M, Matsumoto M, Toyama Y (2006) Pathognomonic radiological signs for predicting prognosis in patients with chronic atlantoaxial rotatory fixation. J Neurosurg Spine 5:385-391. https://doi.org/10.3171/ spi.2006.5.5.385

48. Isono M, Ishii K, Kamida T, Fujiki M, Goda M, Kobayashi $\mathrm{H}$ (2001) Retro-odontoid soft tissue mass associated with atlantoaxial subluxation in an elderly patient: a case report. Surg Neurol 55:223-227

49. Jelsma LD, Geuze RH, Klerks MH, Niemeijer AS, SmitsEngelsman BC (2013) The relationship between joint mobility and motor performance in children with and without the diagnosis of developmental coordination disorder. BMC Pediatr 13:35. https://doi.org/10.1186/1471-2431-13-35

50. Joaquim A, Ghizoni E, Tedeschi H, Appenzeller S, Riew K (2015) Radiological evaluation of cervical spine involvement in rheumatoid arthritis. Neurosurg Focus 38:E4. https://doi.org/10.3171/ 2015.1.FOCUS14664

51. Jun BY (1999) Complete reduction of retro-odontoid soft tissue mass in os odontoideum following the posterior C1-C2 transarticular screw fixation. Spine 24:1961-1964. https://doi. org/10.1097/00007632-199909150-00017

52. Katsanos AH, Kosmidou M, Kyritsis AP, Giannopoulos S (2013) Is vertebral artery hypoplasia a predisposing factor for posterior circulation cerebral ischemic events? A comprehensive review. Eur Neurol 70:78-83. https://doi.org/10.1159/000351786

53. Kim DH, Hilibrand AS (2005) Rheumatoid arthritis in the cervical spine. J Am Acad Orthop Surg 13:463-474. https://doi.org/10. 5435/00124635-200511000-00006

54. Kim H, Ha Y, Lee C, Lee H (2011) Origin of isolated vertigo in rotational vertebral artery syndrome. Neurol Sci 32:1203-1207

55. Kirby A, Davies R (2007) Developmental coordination disorder and joint hypermobility syndrome-overlapping disorders? Implications for research and clinical practice. Child Care Health Dev 33:513-519. https://doi.org/10.1111/j.1365-2214.2006. 00694.x

56. Koby M - The discordant report-pathological radiological findings: a peripatetic review of salient features of neuropathology in the setting of an erstwhile standard 'normal' radiological assessment. Y1-2016. - Co-Morbidities that Complicate the Treatment and Outcomes of Chiari Malformation:- 50

57. Kothari P, Freeman B, Grevitt M, Kerslake R (2000) Injury to the spinal cord without radiological abnormality (SCIWORA) in adults. J Bone Joint Surg Br 82:1034-1037

58. Krakenes J, Kaale B, Moen G, Nordli H, Gilhus N, Rorvik J (2002) MRI assessment of the alar ligaments in the late stage of whiplash injury-a study of structural abnormalities and observer agreement. Neuroradiology 44:617-624

59. Lipski J, Kanjhan R, Kruszewska B, Smith M (1995) Barosensitive neurons in the rostral ventrolateral medulla of the rat in vivo: morphological properties and relationship to $\mathrm{C} 1$ adrenergic neurons. Neuroscience 69:601-618. https://doi.org/10. 1016/0306-4522(95)92652-z

60. Madawi AA, Casey AT, Solanki GA, Tuite G, Veres R, Crockard HA (1997) Radiological and anatomical evaluation of the 
atlantoaxial transarticular screw fixation technique. J Neurosurg 86:961-968. https://doi.org/10.3171/jns.1997.86.6.0961

61. Martel W, Tishler JM (1966) Observations on the spine in mongoloidism. Am J Roentgenol Radium Therapy, Nucl Med 97:630-638. https://doi.org/10.2214/ajr.97.3.630

62. Martin MD, Bruner HJ, Maiman DJ (2010) Anatomic and biomechanical considerations of the craniovertebral junction. Neurosurgery 66:2-6. https://doi.org/10.1227/01.neu. 0000365830.10052 .87

63. Mathers KS, Schneider M, Timko M (2011) Occult hypermobility of the craniocervical junction: a case report and review. J Orthop Sports Phys Ther 41:444-457. https://doi.org/10.2519/jospt.2011. 3305

64. Matsunaga S, Onishi T, Sakou T (2001) Significance of occipitoaxial angle in subaxial lesion after occipitocervical fusion. Spine 26:161-165. https://doi.org/10.1097/00007632200101150-00010

65. Mazzara JT, Fielding JW (1988) Effect of C1-C2 rotation on canal size. Clin Orthop Relat Res 237:115-119

66. Medicine AAoPCoS (1995) Revised statement regarding atlantoaxial instability (AAI) in children with Down syndrome. Pediatrics 96:151-154

67. Menezes AH, Traynelis VC (2008) Anatomy and biomechanics of normal craniovertebral junction (a) and biomechanics of stabilization (b). Childs Nerv Syst 24:1091-1100. https://doi.org/10.1007/ s00381-008-0606-8

68. Mikulowski P, Wollheim FA, Rotmil P, Olsen I (1975) Sudden death in rheumatoid arthritis with atlanto-axial dislocation. Acta Med Scand 198:445-451

69. Milhorat TH, Chou MW, Trinidad EM, Kula RW, Mandell M, Wolpert C, Speer MC (1999) Chiari I malformation redefined: clinical and radiographic findings for 364 symptomatic patients. Neurosurgery 44:1005-1017

70. Miyoshi K, Nakamura K, Haga N, Mikami Y (2004) Surgical treatment for atlantoaxial subluxation with myelopathy in spondyloepiphyseal dysplasia congenita. Spine 29:E488-E491. https://doi.org/10.1097/01.brs.0000143621.37688.f3

71. Nagashima C, Tsuji R, Kubota S, Tajima K (1981) Atlanto-axial, atlanto-occipital dislocations, developmental cervical canal stenosis in the Ehlers-Danlos syndrome (author's transl). No Shinkei Geka 9:601-608

72. Nakanishi K, Tanaka M, Sugimoto $\mathrm{Y}$, Misawa H, Takigawa T, Fujiwara K, Nishida K, Ozaki T (2008) Application of laminar screws to posterior fusion of cervical spine: measurement of the cervical vertebral arch diameter with a navigation system. Spine 33:620-623. https://doi.org/10.1097/BRS.0b013e318166aa76

73. Neo M, Fujibayashi S, Miyata M, Takemoto M, Nakamura T (2008) Vertebral artery injury during cervical spine surgery: a survey of more than 5600 operations. Spine 33:779-785. https:// doi.org/10.1097/BRS.0b013e31816957a7

74. Panjabi M, Dvorak J, Crisco JJ 3rd, Oda T, Wang P, Grob D (1991) Effects of alar ligament transection on upper cervical spine rotation. J Orthop Res 9:584-593. https://doi.org/10.1002/jor. 1100090415

75. Paramore CG, Dickman CA, Sonntag VK (1996) The anatomical suitability of the $\mathrm{C} 1-2$ complex for transarticular screw fixation. J Neurosurg 85:221-224. https://doi.org/10.3171/jns.1996.85.2. 0221

76. Passias PG, Wang S, Kozanek M, Wang C (2013) Relationship between the alignment of the occipitoaxial and subaxial cervical spine in patients with congenital atlantoxial dislocations. J Spinal
Disord Tech 26:15-21. https://doi.org/10.1097/BSD. 0b013e31823097f9

77. Pueschel SM, Scola FH (1987) Atlantoaxial instability in individuals with Down syndrome: epidemiologic, radiographic, and clinical studies. Pediatrics 80:555-560

78. Sacheti A, Szemere J, Bernstein B, Tafas T, Schechter N, Tsipouras P (1997) Chronic pain is a manifestation of the Ehlers-Danlos syndrome. J Pain Symptom Manag 14:88-93

79. Schneider RC, Schemm GW (1961) Vertebral artery insufficiency in acute and chronic spinal trauma, with special reference to the syndrome of acute central cervical spinal cord injury. J Neurosurg 18:348-360. https://doi.org/10.3171/jns.1961.18.3.0348

80. Selecki BR (1969) The effects of rotation of the atlas on the axis: experimental work. Med J Aust 1:1012-1015

81. Smith FW, Dworkin JS (2015) The craniocervical syndrome and MRI. Karger Medical and Scientific Publishers

82. Sobolewski BA, Mittiga MR, Reed JL (2008) Atlantoaxial rotary subluxation after minor trauma. Pediatr Emerg Care 24:852-856. https://doi.org/10.1097/PEC.0b013e31818ea0d3

83. Steinmetz MP, Mroz TE, Benzel EC (2010) Craniovertebral junction: biomechanical considerations. Neurosurgery 66:7-12. https://doi.org/10.1227/01.neu.0000366109.85796.42

84. Taniguchi D, Tokunaga D, Hase H, Mikami Y, Hojo T, Ikeda T, Oda R, Takatori R, Imai K, Kida Y, Otakara E, Ito H, Nishimura T, Kubo T (2008) Evaluation of lateral instability of the atlantoaxial joint in rheumatoid arthritis using dynamic open-mouth view radiographs. Clin Rheumatol 27:851-857. https://doi.org/10. 1007/s10067-007-0809-5

85. Tokuda K, Miyasaka K, Abe H, Abe S, Takei H, Sugimoto S, Tsuru M (1985) Anomalous atlantoaxial portions of vertebral and posterior inferior cerebellar arteries. Neuroradiology 27: 410-413. https://doi.org/10.1007/bf00327604

86. Tomita K, Tsuchiya H, Nomura S (1987) Dynamic entrapment of the vertebral artery by the nerve branch: a new etiology for transient cervical vertigo. Neuro-orthopedics 4:36-43

87. Tubbs RS, Hallock JD, Radcliff V, Naftel RP, Mortazavi M, Shoja MM, Loukas M, Cohen-Gadol AA (2011) Ligaments of the craniocervical junction. J Neurosurg Spine 14:697-709. https:// doi.org/10.3171/2011.1.spine10612

88. Wang S, Wang C (2012) A novel surgical classification and treatment strategy for atlantoaxial dislocations based on 1106 cases over 14 years. Paper presented at the Cervical Spine Research Society, Chicago, IL, Friday, December 7

89. Weissman BN, Aliabadi P, Weinfeld MS, Thomas WH, Sosman JL (1982) Prognostic features of atlantoaxial subluxation in rheumatoid arthritis patients. Radiology 144:745-751. https://doi.org/ 10.1148/radiology.144.4.7111719

90. Werne S (1957) Studies in spontaneous atlas dislocation. Acta Orthop Scand Suppl 23:1-150

91. White AA, Panjabi MM (1990) Clinical biomechanics of the spine. 2nd Ed edn. JB Lippincott Company, Philadelphia

92. Williams B (1981) Simultaneous cerebral and spinal fluid pressure recordings. 2. Cerebrospinal dissociation with lesions at the foramen magnum. Acta Neurochir 59:123-142. https://doi.org/10. 1007/bf01411198

93. Wolfla CE (2006) Anatomical, biomechanical, and practical considerations in posterior occipitocervical instrumentation. Spine J 6: 225s-232s. https://doi.org/10.1016/j.spinee.2006.09.001

94. Wright NM, Lauryssen C (1998) Vertebral artery injury in C1-2 transarticular screw fixation: results of a survey of the AANS/CNS 
section on disorders of the spine and peripheral nerves. Neurosurg Focus 4:E2

95. Yang SY, Boniello AJ, Poorman CE, Chang AL, Wang S, Passias PG (2014) A review of the diagnosis and treatment of atlantoaxial dislocations. Global Spine J 4:197-210. https://doi.org/10.1055/s0034-1376371

96. Yeom JS, Buchowski JM, Park KW, Chang BS, Lee CK, Riew KD (2008) Undetected vertebral artery groove and foramen violations during $\mathrm{C} 1$ lateral mass and $\mathrm{C} 2$ pedicle screw placement. Spine 33:E942-E949. https://doi.org/10.1097/BRS. 0b013e3181870441

97. Yoshida M (1995) Retro-odontoid pseudotumor associated with chronic atlanto-axial instability. Rinsho Seikei Geka 30:395-402

98. Yoshimoto H, Ito M, Abumi K, Kotani Y, Shono Y, Takada T, Minami A (2004) A retrospective radiographic analysis of subaxial sagittal alignment after posterior C1-C2 fusion. Spine 29:175-181. https://doi.org/10.1097/01.brs.0000107225.97653. ca
99. Yuksel M, Heiserman JE, Sonntag VK (2006) Magnetic resonance imaging of the craniocervical junction at 3-T: observation of the accessory atlantoaxial ligaments. Neurosurgery 59:888 892; discussion 892-883. https://doi.org/10.1227/01.neu. 0000232661.24547 .06

100. Yurube T, Sumi M, Nishida K, Miyamoto H, Kohyama K, Matsubara T, Miura Y, Sugiyama D, Doita M (2012) Incidence and aggravation of cervical spine instabilities in rheumatoid arthritis: a prospective minimum 5-year follow-up study of patients initially without cervical involvement. Spine 37:2136-2144. https://doi.org/10.1097/BRS.0b013e31826def1c

101. Zhang H, Bai J (2007) Development and validation of a finite element model of the occipito-atlantoaxial complex under physiologic loads. Spine 32:968-974. https://doi.org/10.1097/01.brs. 0000261036.04919 .91

Publisher's note Springer Nature remains neutral with regard to jurisdictional claims in published maps and institutional affiliations. 